\title{
O ESTATUTO DA METRÓPOLE E A NOVA ESTRUTURA INSTITUCIONAL DAS REGIÕES METROPOLITANAS NO BRASIL
}

\author{
Autores: João Telmo de Oliveira Filho e Carla Portal Vasconcellos \\ Universidade Federal de Santa Maria - UFSM - Brasil; Universidade de Passo Fundo - UPF - Brasil. \\ Orientado pelo professor doutor Oberon Mello - UFRGS \\ Email: joaotelmofilho@gmail.com
}

\section{RESUMO.}

Este artigo tem como objetivo apresentar e discutir os instrumentos jurídicos, políticos e administrativos do sistema de gestão metropolitana no Brasil e as alterações propostas pelo Estatuto da Cidade - Lei Federal 10.257/01 e, mais recentemente, pelo do Estatuto da Metrópole - Lei Federal 13.089/15, com a introdução de instrumentos de gestão democrática participativa. Propõe analisar os fundamentos da estrutura institucional metropolitana brasileira e seus distintos arranjos e as principais normas urbanas relativas à gestão metropolitana, com vistas a contribuir para ampliar a discussão sobre a evolução dos sistemas e dos modelos de planejamento e de gestão urbanos metropolitanos. O Estatuto da Metrópole busca atualizar o tema da gestão metropolitana, propondo a gestão compartilhada entre Estados e municípios através de Plano de Desenvolvimento Integrado, aprovado por lei estadual. Como estudo de caso, a pesquisa busca avaliar o processo de elaboração do Plano Integrado Metropolitano da Região Metropolitana de Porto Alegre.

Palavras-chave: Planejamento Urbano. Região Metropolitana. Estatuto da Cidade. Estatuto da Metrópole.

\begin{abstract}
This article aims to present and discuss the legal, political and administrative instruments of the metropolitan management system in Brazil and the legislative changes proposed by the Estatuto da Cidade, Lei Federal $10.257 / 01$ and, more recently, by the Estatuto da Metrópole, Lei Federal 13.089/15, with the introduction of participative democratic management instruments. This paper proposes to analyze the foundations of the Brazilian metropolitan institutional structure and its different arrangements and the main urban norms related to the metropolitan management, to contribute to broaden the discussion about the evolution of metropolitan urban planning and management models. The Estatuto da Metrópole seeks to update the theme of metropolitan management, proposing shared management among states and municipalities through an Integrated Development Plan, approved by a state law. As a case study, the research seeks to evaluate the process of elaboration of the Plano Integrado Metropolitano da Região Metropolitana de Porto Alegre.
\end{abstract}

Keywords: Urban Planning. Metropolitan Region. Statute of the City. Statute of the Metropolis 


\section{INTRODUÇÃO}

As regiões metropolitanas brasileiras demonstram realidades sociais, econômicas, culturais e configurações territoriais com diversidade e complexidade socioespacial distinta dos arranjos institucionais regionais e metropolitanos previstos. Durante a ditadura militar, na década de 1970, foram estabelecidas as chamadas áreas metropolitanas, através da criação das regiões metropolitanas, com objetivo de tentar resolver parte dos problemas de planejamento e gestão decorrentes da urbanização acelerada e desordenada das grandes cidades, o que, certamente não acompanha a dimensão das novas relações e arranjos territoriais e os desafios do planejamento e da gestão do espaço metropolitano atuais.

A partir do processo de democratização e da promulgação da Constituição Federal de 1988 e da introdução de novos instrumentos de planejamento e de gestão territorial, nos últimos anos, surge o desafio de propor mudanças nas formas de planejamento e a gestão das metrópoles. A introdução dos instrumentos de gestão democrática participativa através do Estatuto da Cidade - Lei Federal 10.257, de 10 de julho de 2001 - e, mais recentemente, através do Estatuto da Metrópole - Lei Federal 13.089, de 12 de janeiro de 2015 - produz tratamento distinto no processo centralizado e autoritário de criação e gestão das regiões metropolitanas brasileiras.

Esses novos instrumentos buscam atualizar os modelos e lógicas de elaboração e de gestão dos Planos Diretores Municipais em geral e dos Planos Metropolitanos em particular. As recentes alterações são iniciativas que propõem modificar significativamente a forma de estruturar e planejar o território, produzindo grande impacto na relação entre esferas administrativas e arranjos territoriais existentes. Estabelecem a gestão democrática e a participação das populações e dos agentes políticos e sociais nas decisões relativas ao planejamento e gestão do território e oferecem critérios para melhor distribuição da terra e dos benefícios da urbanização.

A edição do Estatuto da Metrópole busca atualizar o tema da gestão metropolitana compartilhando com os municípios o processo de regulamentação das cooperações territoriais. Trata também da gestão plena das metrópoles através do Plano de Desenvolvimento Integrado, aprovado por lei estadual, que dispõe sobre o modelo de gestão e das formas de participação da população.

Desta forma, pretendemos neste trabalho apresentar os instrumentos jurídicos, políticos e administrativos da gestão metropolitana e discutir as recentes alterações legislativas sobre o tema, analisar os fundamentos da estrutura institucional metropolitana brasileira em seus distintos arranjos e avaliar os planos e programas urbanísticos e as principais normas urbanas relativas à gestão metropolitana, com vistas a contribuir para ampliar a discussão sobre a evolução dos sistemas e dos modelos de planejamento e de gestão urbanos metropolitanos.

\section{BREVES CONSIDERAÇÕES SOBRE O PLANEJAMENTO E DA GESTÃO DAS REGIÕES NO BRASIL}

\subsection{O tradicional modelo institucional das Regiões Metropolitanas e Aglomerações Urbanas brasileiras}

O tema da gestão das regiões metropolitanas aparece explicitado no sistema jurídico brasileiro no texto da Constituição Federal de 1967 e mantém-se com a Emenda Constitucional n 1, de 1969. Ao tratar da ordem econômica e social a Constituição de 1967 dispôs, no artigo 157, parágrafo 10, que "A União, mediante Lei Complementar, poderá estabelecer regiões metropolitanas, constituídas por municípios que independentemente de sua vinculação administrativa, integrem a mesma comunidade socioeconômica, visando à realização de interesse comum". A regulação ocorreu em 1973, com a promulgação da Lei Complementar $n .^{\circ} 14$, sendo institucionalizadas as regiões metropolitanas de São Paulo, Belo Horizonte, Porto Alegre, Recife, Salvador, Curitiba, Belém e Fortaleza, posteriormente a Lei Complementar n. ${ }^{\circ}$ 20/74 criou a Região Metropolitana do Rio de Janeiro.

O interesse na questão regional e metropolitana teve como objetivo, com os militares no poder, de reduzir a autonomia dos Estados e dos municípios e centralizar decisões estratégicas no governo federal. É indispensável acrescentar que as Constituições Federais de 1967 e a Emenda Constitucional de 1969 deslocaram para a União a competência de criar regiões por agrupamento de municípios de um mesmo Estado, não porque estivessem especificamente preocupadas com o desenvolvimento regional, mas porque estavam interessadas em fortalecer a unidade do controle policial da nação. O deslocamento da competência não passava de uma estratégia para garantir e consolidar o poder central em regiões governadas por prefeitos e governadores indicados pela ditadura.

O modelo previu a estruturação das chamadas entidades metropolitanas. Instituídas as entidades administrativas, o Governo Federal tratou de fornecer a base institucional de apoio. Em primeiro lugar criou a Comissão Nacional de Política Urbana em 1974, com o objetivo de acompanhar e apoiar a implantação das administrações metropolitanas, propor diretrizes de política de desenvolvimento urbano e avaliar 0 
desempenho da nova experiência. Em segundo lugar, criou o Fundo Nacional de Desenvolvimento Urbano FNDU (Lei 6.256, de 22/10/75) com o objetivo de dotar o Conselho Nacional de Políticas Urbanas - CNPU, anteriormente criado, de condições de intervir nas Regiões Metropolitanas. A Lei Complementar n. ${ }^{\circ}$ 14/73 estabeleceu que o sistema de gestão metropolitana devia ser atribuído a dois conselhos: a um deliberativo e a um consultivo, e que estes deveriam contar com apoio técnico de entidades de planejamento a serem criadas pelos governos estaduais. $O$ modelo era completado pelos fundos federais que financiavam 0 desenvolvimento urbano, sobretudo os projetos nas áreas de saneamento, de habitação e de transporte.

O modelo de planejamento e da estrutura de gestão metropolitana dos anos 1970, centralizado, autoritário e tecnocrático, criou a base para o regime administrativo estruturado a partir de regiões estabelecidas por leis complementares, como as metropolitanas, e que ainda serve de base ainda para a estrutura jurídico administrativa das regiões no Brasil.

\subsection{A Constituição Federal de 1988, a multiplicidade dos arranjos institucionais metropolitanos e o dilema da gestão integrada.}

Com a redemocratização do país, a Constituição Federal de 1988 propõe uma maior de descentralização política do Estado brasileiro e maior autonomia para os Estados e municípios. Neste contexto, o artigo 25, parágrafo $3^{\circ}$ da Constituição Federal, ao tratar das regiões metropolitanas, aglomerações urbanas e microrregiões, dispõe o seguinte:

"Art. 25...

(...)

$\S 3^{\circ}$ Os Estados poderão, mediante Lei Complementar, instituir regiões metropolitanas, aglomerações urbanas e microrregiões, constituídas por agrupamento de municípios limítrofes para integrar a organização, o planejamento e a execução de funções públicas de interesse comum".

A Constituição desloca a competência para a instituição das Regiões Metropolitanas, aglomerações urbanas e microrregiões aos Estados, mantendo o princípio da organização, o planejamento e a execução das funções públicas de interesse comum.

Treze anos após a Constituição de 1989, é editada em 2001 a Lei n 10.257/01, o chamado "Estatuto da Cidade", que é a lei federal de desenvolvimento urbano prevista constitucionalmente, e que regulamenta os instrumentos de política urbana que devem ser aplicados pela União, Estados e Municípios, além de tratar da questão metropolitana através do planejamento metropolitano e a execução das funções públicas de interesse comum.

O Estatuto da Cidade, em seu artigo $4^{\circ}$, coloca o planejamento metropolitano, junto do planejamento nacional de ordenação do território e do planejamento municipal, como instrumentos de execução da política urbana. $\mathrm{O}$ artigo $4^{\circ}$, inciso $\mathrm{II}$, refere especificamente sobre o planejamento das regiões metropolitanas, aglomerações urbanas e microrregiões. O artigo 43 do Estatuto da Cidade determina que os Estados federados cumpram a diretriz geral de gestão democrática da cidade mediante a criação de órgãos colegiados estaduais de política urbana, além de conferências, debates, audiências e consultas públicas. O artigo 45 dispõe expressamente que os organismos gestores das regiões metropolitanas incluirão obrigatoriamente a participação da população e de associações representativas da sociedade, como segue:

\section{Estatuto da Cidade (Lei 10.257/01)}

Art. 45. Os organismos gestores das regiões metropolitanas e aglomerações urbanas incluirão obrigatória e significativa participação da população e de associações representativas dos vários segmentos da comunidade de modo a garantir o controle direto direta de suas atividades e o pleno exercício da cidadania.

Em seus dispositivos referentes à política urbana metropolitana, o Estatuto da Cidade destaca a questão da participação da população através das audiências e consultas públicas e refere às entidades metropolitanas as mesmas diretrizes. Entretanto, a lei não aprofunda questões referentes ao modelo institucional, nem atualiza o modelo de gestão, apenas faz referência à gestão democrática através da participação nos organismos gestores existentes.

A lei 11.107/05 regulamenta as normas gerais de contratação dos consórcios públicos. Segundo a norma, o consórcio público (que pode ser de dois ou mais municípios, empresas, autarquias, etc..) poderá ser uma associação pública ou uma pessoa jurídica de direito privado e é constituído por contrato entre os entes participantes. O consórcio público poderá firmar convênios, contratos, acordos de qualquer natureza, 
receber auxílios, contribuições e subvenções sociais ou econômicas de outras entidades e órgãos do governo; nos termos do contrato de consórcio de direito público, promover desapropriações e instituir servidões nos termos de declaração de utilidade ou necessidade pública, ou interesse social, realizada pelo Poder Público e ser contratado pela administração direta ou indireta dos entes da Federação consorciados, dispensada a licitação.

Entre as vantagens da criação dos consórcios está a prestação de serviços públicos e o de exercer atividades de arrecadação de tarifas e outros preços públicos pela prestação de serviços ou pelo uso ou outorga de uso de bens públicos por eles, através de rateio dos recursos.

O consórcio de municípios é uma forma associativa que pode ser constituído mediante a congregação de vários municípios para exercer atividades ou serviços de interesse comum, específicos, devendo ser aprovado por lei dos Municípios que dele participem. No mesmo sentido, a constituição de entidade intermunicipal ou inter-regional, tendo a natureza de autarquia, é também um mecanismo de cooperação que pode ser utilizado para o desempenho de políticas de competência comum.

Na prática, o disposto na Emenda Constitucional e na lei posterior serviu de estímulo para a efetivação da experiência dos consórcios regionais e dos convênios entre municípios, o que tem ocorrido frequentemente no país. Vislumbra-se uma tendência, partindo do interesse econômico, de organização voluntária de municípios, em geral com o objetivo de incentivar o crescimento econômico e a resolução em conjunto de alguns problemas regionais ${ }^{1}$. Temos, como exemplo, entre outros, o consórcio formado pelos municípios da região da Grande ABC em São Paulo.

O Consórcio do Grande ABC foi constituído em 1990, reunindo sete municípios localizados no Sudeste da Região Metropolitana de São Paulo, que somam mais de dois milhões de habitantes. Fortemente ligado na sua formação inicial aos governos municipais do Partido dos Trabalhadores a chamada "Câmara da Região do Grande ABC, que é criada oficialmente em 12 de março de 1997. É criada em outubro de 1998, a Agência Regional de Desenvolvimento Econômico organização não governamental com o objetivo principal de elaborar e implementar ações voltadas para a economia regional.

A atuação efetiva do consórcio está ligada tanto as transformações nas relações intergovernamentais como na política local. Enquanto os órgãos de gestão são constituídos para um fim determinado, o Consórcio do $A B C$ se propôs atuar em um leque grande de questões, do gerenciamento ambiental ao desenvolvimento regional, sempre aberto a novas iniciativas. A gestão compreende, assim, o relacionamento em vários âmbitos - administração estadual e municipal, meio acadêmico, instituições internacionais e sociedade. O Consórcio da Grande ABC é uma referência importante para a discussão da regionalização, especialmente na tentativa de interferência de uma determinada região em seu processo de desenvolvimento, o que torna a experiência, somada à adesão social que recebeu e o modelo de gestão eficiente e bastante democrático como uma grande experiência de gestão pública, constituída a partir da iniciativa de municípios.

Outro exemplo de arranjo institucional são Conselhos Regionais de Desenvolvimento - COREDES criados no Estado do Rio Grande do Sul em 1990, a partir de uma mobilização das entidades civis e de classes. Essa mobilização acabou por fazer parte do programa de governo governador Alceu Collares (PDT - 1991-1995), deixando livre a auto-organização às entidades civis, institucionalizou ainda em 1991 os primeiros 17 Conselhos Regionais, para em 1994 regulamentá-los. Em 1996, a partir tanto de desmembramentos internos quanto da criação de novos, os COREDES passaram para o número de 21 conselhos. Atualmente, existem 28 COREDES e, em 2003, foram criados os Conselhos Municipais de desenvolvimento - COMUDES - que articulam o nível municipal com o regional.

Os Conselhos de Desenvolvimento do Rio Grande do Sul tiveram sua gênese nas discussões acadêmicas universitárias e na pressão social dos cidadãos. Em nenhum momento sua criação foi determinada por alguma instância governamental, mas foram criados e auto-organizados pela sociedade civil, eles foram absorvidos como estrutura de governança independente pelo governo estadual, que os regulou e criou um espaço de interface através dos Fóruns dos COREDES (Cargnin, 2014).

Alguns elementos destacam-se para o entendimento da importância dos COREDES como arranjo territorial regional: A existência tanto de uma rede de universidades comunitárias ${ }^{2}$ e federais, dispostas a promover o desenvolvimento da microrregião onde se encontravam.

\footnotetext{
${ }^{1}$ Nas décadas de 1990 e 2000 houve um processo de estímulo a agencificação da administração pública brasileiras, o que inclui, junto com a criação das autarquias e empresas de planejamento municipais, o surgimento de agências para o desenvolvimento das atividades regionais - as agências regionais de desenvolvimento, como modalidade de entidade voluntária e que congrega as funções executivas e reguladoras que contempla os interesses dos municípios. No caso dos sistemas de gestão de recursos hídricos no país, estão legalmente previstas a constituição de agências com competência para a cobrança de tributos, gerenciamento e regulação das atividades, muitas delas ligadas aos comitês de gerenciamento de bacia hidrográfica.
}

2 São chamadas universidades comunitárias aquelas que foram criadas pela sociedade civil e pelo poder público local (não estatal) sem fins lucrativos. Elas constituem instituições públicas reconhecidas pelas comunidades regionais como um importante fator de desenvolvimento. 
É importante ressaltar que os Conselhos também se mesclam a outros recortes de planejamento no Estado do RS, inserindo-se tanto nas já existentes nove regiões funcionais de planejamento, quanto se articulando aos recortes municipais, através dos COMUDES, e aos recortes sub-regionais dos MesoSul e MesoMercosul, dos Territórios Rurais e dos Territórios da Cidadania. Assim, apesar de constituir um excelente exemplo de governança, os COREDES tiveram pouco êxito no combate às disparidades regionais e problemas sociais das regiões. Embora alguns COREDES tenham elaborado Planos Estratégicos de Desenvolvimento Regional, a maiorias destes planos constituem-se em diretrizes, sem nenhuma estratégia de aplicação ou destinação de recursos.

Hoje temos no Brasil um quadro complexo nos arranjos regionais, em geral, e nos metropolitanos, em particular. Além da tradicional estrutura de regiões metropolitanas, de aglomerações urbanos e de microrregiões podemos destacar as seguintes formas de cooperações territoriais: as Associações de Municípios, os Consórcios Intermunicipais, os Comitês de Bacias Hidrográficas, os convênios de cooperação, os contratos de gestão, Conselhos de Desenvolvimento e, em menor escala, as Regiões de Desenvolvimento Integrado e os Territórios da Cidadania, dentre outros.

Estas formas de cooperação distintas tanto nos objetivos como na sua estrutura jurídica e administrativa refletem experiências, muitas delas exitosas. O desafio contemporâneo consiste em aproveitar as experiências e procurar a integração das mesmas através de planos e programas integrados, que incluíssem os agentes e os atores no espaço metropolitano.

\subsection{O Estatuto de Metrópole: Será um novo modelo de gestão metropolitana?}

A Lei no 13.089/2015, o chamado Estatuto da Metrópole, é uma norma que propõe atualizar o modelo de gestão metropolitana adequando as novas diretrizes constitucionais do Estado brasileiro. Ela dispõe que a responsabilidade de instituir e gerir as Regiões Metropolitanas deve ser compartilhada com os Estados e municípios. No seu artigo primeiro, parágrafo segundo, dispõe que serão observadas as normas gerais do Estatuto da Cidade, bem como as regras que disciplinam as diretrizes gerais da política urbana e dá outras providências, e em outras leis federais, bem como as regras que disciplinam a política nacional de desenvolvimento urbano, a política nacional de desenvolvimento regional e as políticas setoriais de habitação, saneamento básico, mobilidade urbana e meio ambiente.

O Estatuto da Metrópole trata no seu artigo segundo inciso terceiro da gestão plena, incluindo na alínea "c", o plano de desenvolvimento integrado, aprovado por lei estadual e dispõe, de forma ainda genérica, no seu artigo $6, \mathrm{~V}$, sobre o modelo de gestão e das formas de participação da população.

Uma das primeiras definições do Estatuto da Metrópole é a do estabelecimento da governança interfederativa entre estados e municípios metropolitanos. A criação das Regiões Metropolitanas (e, ou aglomerações urbanas), está condicionada à aprovação de lei complementar estadual que deve definir: os municípios que a integram, a estrutura administrativa e do sistema integrado de alocação de recursos e de prestação de contas; e os meios de controle social.

Insiste na ideia de governança interfederativa fundada nos seguintes princípios da prevalência do interesse comum sobre o local, compartilhamento de responsabilidades para a promoção do desenvolvimento urbano integrado, autonomia dos entes da Federação, observância das peculiaridades regionais e locais, gestão democrática da cidade, efetividade no uso dos recursos públicos e a busca do desenvolvimento sustentável. Segue uma série de diretrizes específicas como a implantação de processo permanente e compartilhado de planejamento e de tomada de decisão, a execução compartilhada das funções públicas de interesse comum, mediante rateio de custos previamente pactuado no âmbito da estrutura de governança interfederativa; a participação de representantes da sociedade civil nos processos de planejamento e de tomada de decisão.

Prevê como instrumentos desta governança interfederativa, além do plano de desenvolvimento urbano integrado (PDUI), os planos setoriais interfederativos, fundos públicos, operações urbanas consorciadas interfederativas, zonas para aplicação dos instrumentos do Estatuto da Cidade, consórcios públicos, convênios de cooperação, contratos de gestão, compensação por serviços ambientais e parcerias públicoprivadas interfederativas.

A lei descreve os conteúdos do plano de desenvolvimento urbano integrado da região metropolitana ou aglomeração urbana considerando o conjunto de Municípios que compõem a unidade territorial urbana e abrange áreas urbanas e rurais e contempla no mínimo: as diretrizes para as funções públicas de interesse comum, incluindo projetos estratégicos e ações prioritárias para investimentos, o macrozoneamento urbano, diretrizes quanto à articulação dos Municípios no parcelamento, uso e ocupação no solo urbano; as diretrizes quanto à articulação intersetorial das políticas públicas afetas à unidade territorial urbana, a delimitação das áreas com restrições à urbanização visando à proteção do patrimônio ambiental ou cultural, bem como das áreas sujeitas a controle especial pelo risco de desastres naturais, se existirem, e o sistema de acompanhamento e controle de suas disposições. Copiando o Estatuto da Cidade, estabelece a 
obrigatoriedade das audiências públicas e a publicidade dos documentos e inova no acompanhamento pelo Ministério Público.

Do mesmo modo que no Estatuto da Cidade, incorre em crime de improbidade administrativa do Governador do Estado e de agente público que atue na estrutura de governança interfederativa (o que inclui prefeitos e demais agentes públicos municipais) que deixar de tomar as providências necessárias para a elaboração do plano de desenvolvimento urbano integrado no prazo de três anos da edição da lei ou cinco anos contados da data de instituição da região metropolitana ou da aglomeração urbana. Além disso, também será responsabilizado o prefeito que deixe de tomar medidas a fim de garantir a compatibilização do Plano Diretor Municipal com o plano regional no prazo de três anos, contados a partir da aprovação da lei estadual do plano de desenvolvimento integrado da unidade territorial.

O prazo inicial para a elaboração do Plano de Desenvolvimento Urbano Integrado encerrou-se em janeiro de 2018. Nesta data apenas 7 das regiões metropolitanas brasileiras haviam efetivamente avançado em seus planos. Através da Medida Provisória oㅜ 818, de 2018, o Estatuto da Metrópole foi alterado e ampliouse o prazo final para a elaboração do PDUI e sua aprovação pela instância colegiada até a data limite de 31 de dezembro de 2021.

Como ocorreu com ao processo de aprovação dos planos diretores municipais, em razão da responsabilização prevista no Estatuto da Cidade em 2006 (e ampliada por lei até 2008), foi novamente ampliado o prazo para elaboração dos Planos Integrados que em 2018. Novamente reflete o descaso político com o planejamento e a elaboração sem os devidos estudos técnicos e discussões públicas dos planos metropolitanos pelos governadores estaduais e prefeitos das cidades metropolitanas.

O processo de elaboração do Plano de Desenvolvimento Urbano Integrado da Região Metropolitana de Porto Alegre, bem como dos planos integrados das aglomerações urbanas, no Estado do Rio Grande do Sul é um modelo da desarticulação entre planos, programas e ações entre Estado e municípios metropolitanos e do não cumprimento dos prazos previstos na lei. Com prazo até março de 2018 para a elaboração do plano integrado, a gestão do processo centralizada na entidade governamental metropolitana METROPLAN (em processo de extinção) e, especificamente, da equipe da Diretoria de Gestão Territorial (DIRGT), não concluiu até o momento nem o Plano Preliminar de Ação que deveria abordar uma síntese dos conteúdos apresentado nas reuniões preliminares realizadas em 2016, mapeamento e um cronograma com as etapas necessárias para construção do Estudo/Termo de Referência, que subsidiará a elaboração do Plano Urbano Integrado da Região Metropolitana de Porto Alegre.

Destaca-se ainda que, até o presente momento, não foram realizadas as audiências públicas nos municípios, nem definida a metodologia da participação das populações, nem a forma de integração dos demais planos e programas de todos os municípios e estruturas regionais metropolitanas. Do mesmo modo que o processo de elaboração dos planos diretores municipais previstos pelo Estatuto da Cidade em 2008, a participação das populações continua relegada ao segundo ao plano e o modelo tecnocrático de aprovação de planos é retomado sem os requisitos previstos nem a necessária deliberação discussão pública.

\section{CONCLUSÕES}

Este trabalho procurou apresentar elementos do modelo de gestão regional e metropolitana no país em um quadro complexo de arranjos e estruturas regionais distintas. A atual estrutura das regiões metropolitanas no país demonstra configurações territoriais com diversidade e complexidade socioespacial distinta dos arranjos regionais e metropolitanos anteriormente previstos. Durante a década de 1970 foi estabelecida no país a criação das regiões metropolitanas, com objetivo de tentar resolver parte dos problemas de planejamento e gestão decorrentes da urbanização acelerada e desordenada das grandes cidades, o que, certamente, não acompanha a dimensão das novas relações e arranjos territoriais e os desafios do planejamento e da gestão do espaço metropolitano atuais.

O modelo de gestão metropolitana brasileira, instituído na ditatura militar em 1971 e nas leis e iniciativas que se seguiram, demonstram virtudes e fragilidades: A instituição forçada de estruturas administrativas de gestão do espaço metropolitano não surgiu de demandas populares, mas de decisões políticas autoritárias. A instituição das regiões metropolitanas, aglomerações urbanas e microrregiões brasileiras, sendo que 0 modelo ainda é referência para o sistema gestão do espaço metropolitano. Ao mesmo tempo em que não houve participação popular na instituição do modelo, não ocorre, de forma efetiva, até hoje na sua gestão.

A introdução dos instrumentos de gestão democrática participativa através do Estatuto da Cidade e, mais recentemente, do Estatuto da Metrópole, produz tratamento distinto no processo centralizado e autoritário de criação e gestão das regiões metropolitanas brasileiras. Esses novos instrumentos buscam atualizar os modelos e lógicas de elaboração e de gestão dos Planos Diretores Municipais, em geral e dos Planos Metropolitanos, em particular. As recentes alterações são iniciativas que propõem modificar a forma de estruturar e planejar o território, produzindo impacto na relação entre esferas administrativas e arranjos 
territoriais existentes. Estabelecem a gestão democrática e a participação das populações e dos agentes políticos e sociais nas decisões relativas ao planejamento e à gestão do território e oferecem critérios para melhor distribuição da terra e dos benefícios da urbanização. Não obstante o disposto na Constituição Federal de 1988, o Estatuto da Cidade e as leis posteriores que referem à necessidade da gestão democrática do espaço urbano e metropolitano, isto raramente ocorre.

Novos arranjos institucionais como os consórcios municipais e regionais, os conselhos de desenvolvimento e os comitês de gerenciamento de bacias, entre outros, surgiram de iniciativas locais e incluem instrumentos participativos como audiências e consultas públicas, mas, em geral, não estão devidamente integrados e nas estruturas administrativas e órgãos de gestão institucionalizados. Certamente, a ausência de instituições políticas de gestão metropolitana que efetivem padrões de governança democrática com ampla participação popular nestes territórios é uma constatação recorrente.

Talvez seja cedo para falar dos efeitos do Estatuto da Metrópole em razão da complexidade das relações entre os vários níveis de governo e dos vários arranjos institucionais regionais metropolitanos existentes no país, mas algumas considerações podem ser feitas:

O novo Estatuto da Metrópole insiste em vários problemas já verificados em relação ao Estatuto da Cidade: Começa pela falta de uma melhor definição do conteúdo dos planos metropolitanos, como garantidores de princípios constitucionais da função social da cidade, da função social da propriedade e da gestão democrática, através de instrumentos específicos, bem como insiste no modelo de gestão centralizado e burocratizado das entidades metropolitanas e não garante a participação efetiva das populações através de instâncias deliberativas. Também, na forma de participação da população na gestão dos processos e no controle dos planos deixa a desejar, e na forma de gerenciamento e da responsabilidade compartilhada dos municípios e das regiões administrativas.

O modelo parece não ser capaz de reconhecer a crescente financeirização do espaço urbano, em torno de relevantes e complexos projetos e autorizações urbanas e a forma de promover o equilíbrio entre interesses públicos e privados neste contexto e, mais importante, não fornece elementos para resolver o problema da baixa articulação entre os vários níveis de governo, insiste na continuidade de padrões de governança urbana burocráticas, tecnocráticas e centralizadas e com baixa participação popular, reforçando um modelo de gestão metropolitano com ausência de perspectiva da efetividade do direto à cidade no espaço metropolitano.

Após mais de 15 anos da elaboração do Estatuto da Cidade poucos municípios adequaram os seus planos diretores e leis aos requerimentos do Estatuto. Apenas para citar dois instrumentos, poucos municípios aprovaram leis como as do Imposto sobre a Propriedade Territorial Urbano - progressivo, o IPTU Progressivo e do "solo criado, não avançaram no sentido da melhor distribuição da terra urbana e na aplicação dos instrumentos fundiários, de distribuição de mais valias e de proteção ambiental, bem como, problemas em relação a determinação da participação efetiva das populações nos processos de elaboração e revisão dos planos.

O Estatuto da Metrópole vem tardiamente buscar atualizar o modelo de gestão metropolitana com as novas diretrizes constitucionais do Estado social e democrático brasileiro. Espera-se que a nova lei não seja um Estatuto da Cidade requentado, incorrendo em muitos erros e indefinições já presentes no Estatuto da Cidade, especialmente quanto à efetividade dos instrumentos de gestão democráticos previstos. $\mathrm{O}$ que se percebe, desde já, é a mesma indefinição e indeterminação dos critérios quanto a efetividade dos instrumentos urbanísticos e o reconhecimento da realidade complexa e multiescalar das relações no espaço metropolitano que deveria incluir outros agentes e instituições, bem como da qualidade da participação popular, problemas recorrentes na efetividade das políticas públicas urbanas no Brasil.

\section{REFERÊNCIAS BIBLIOGRÁFICAS}

BRASIL. Constituição Federal de 1988. Senado Federal. Brasília - DF, 2001.

BRASIL. Lei Federal 10.257 de 10 de julho de 2001 - Estatuto da Cidade. Setor de Publicação. Senado Federal. Brasília - DF, 2001. Disponível em www.planalto.gov.br /lei/L10.257compilado.htm. Consulta: 15 maio 2017.

BRASIL. Lei Federal 13.089 de 12 de janeiro de 2015 - O Estatuto da Metrópole. Setor de Publicação. Brasília - DF, 2001. Disponível em: <www.planalto.gov.br /lei/L13.089compilado.htm>. Consulta em: 15 de maio de 2017.

BRASIL. Medida Provisória 818 de 11 de janeiro de 2018. Disponível em: http://www.planalto.gov.br/ccivil 03/ ato2015-2018/2018/Mpv/mpv818. Consulta em: 15 de janeiro de 2018. 
CARGNIN, A. P. (2014). POLÍTICA NACIONAL DE DESENVOLVIMENTO REGIONAL E REPERCUSSÕES NO RIO GRANDE DO SUL. Mercator, Fortaleza: Universidade Federal do Ceará. v. 13, n. 1, p. 19-35, jan./abr. 2014.

CARGNIN, A. P.; RÜCKERT, A. A. (2013). O planejamento territorial no Brasil: efeitos da Política Nacional de Desenvolvimento Regional no Estado do Rio Grande do Sul; Confins [Online], 19 | 2013, posto online no dia 12 Novembro 2013. Disponível em: http://confins.revues.org/8519; DOI: 10.4000/confins.8519. Consulta: 06 Maio 2015.

COSTA, Marco Aurélio. Democracia Urbana. Para uma crítica do planejamento territorial. (2008). Tese de doutorado. IPPUR. UFRJ, 2008.

DA SILVA, Jose Afonso. (1989). O Município na constituição de 1988 . Imprenta: São Paulo, Revista dos Tribunais, 1989, 91 p. ISBN: 8520307809.

DALLABRIDA, V. R. (2012). A administração se descentraliza, o poder nem tanto! Considerações e percepções sobre experiências de descentralização político-administrativa no Brasil. XII Seminário Internacional da Red Iberoamericana de Investigadores sobre Globalización y Território - RII, realizado em Belo Horizonte, entre os dias $1^{\circ}$ à 4 de outubro de 2012, UFMG.

KLINK, J. J. ; LEPORE, W. C. ; BRESCIANI, L. P. (2007). Novas Institucionalidades e Desenvolvimento Regional - A articulação e os limites da Câmara Regional do Grande ABC; X SEMEAD - Seminários em Administração FEA - USP, 2007, São Paulo. Globalização e Internacionalização das Empresas.

MEIRELLES, Hely Lopes. Direito municipal brasileiro. 13. ed. São Paulo: Malheiros, 2002.

OLIVEIRA FILHO, João Telmo. (2009). A participação popular no planejamento urbano: $A$ experiência de Porto Alegre. Tese. (Doutorado em Planejamento Urbano e Regional). Faculdade de Arquitetura. Programa de Pós graduação em Planejamento Urbano e Regional. Universidade Federal do Rio Grande do Sul. Propur -Ufrgs. Porto Alegre, 2009.

OLIVEIRA FILHO, João Telmo. (2003). O desafio da gestão metropolitana nas novas dimensões jurídicoinstitucionais da organização do Estado brasileiro: O caso da Região Metropolitana de Porto Alegre. Dissertação (Mestrado em Planejamento Urbano e Regional). Faculdade de Arquitetura. Programa de Pósgraduação em Planejamento Urbano e Regional. Universidade Federal do Rio Grande do Sul. PropurUfrgs. Porto Alegre, 2003.

SANTOS, Milton. A urbanização brasileira. (1992). São Paulo: Hucitec.

SOUZA, Marcelo Lopes de. (2003). Mudar a cidade: uma introdução crítica ao planejamento e à gestão urbanos. 2. ed. Rio de Janeiro: Bertrand Brasil. 